\title{
APONTAMENTOS SÔBRE A INDIVIDUALIZAÇÃO DA PENA
}

\author{
RENÊ ARIEL DOTTI \\ (Professor Contratado de Direito Penal)
}

\author{
SUMÁRIO: \\ 1. Esbôç̧o histórico (I): visão do fato e autor; \\ 2. Esbôço histórico (II): estabelecimento da pena em graus; \\ 3. Aplicação da pena em atenção ao fato e ao agente; \\ 4. Disposição do Anteprojeto Hungria e crítica; \\ 5. Inteligência das expressões periculosidade e capacidade para delinqüir; \\ 6. Dedução da capacidade para delinqüir; \\ 7. Equilíbrio na apreciação judicial entre o ilícito e seu construtor; \\ 8. Tendência dos textos modernos para a medição concreta da pena; \\ 9. O X Congresso Internacional de Direito Penal e o tema relativo à divisăo \\ do processo penal em duas fases; \\ 10. Tarefas compreendidas na primeira e na segunda fase; \\ 11. Perspectiva para a realização do destino da pena.
}

1. A crônica da pena revela um itinerário de suplícios infor. mados pelo refinamento da crueldade, desde o alvorecer da civilização humana até a metade do século dezoito quando BECCARIA proclamou a necessidade de ser ela proporcionada ao delito e deter minada pela lei, a fim de que o arbítrio judicial não ganhasse dimensões extraordinárias em holocausto à liberdade individual e à dignidade do magistério punitivo.

Os mais credenciados representantes da filosofia francesa da época (MORELLET, VOLTAIRE, DIDEROT, D'ALEMBERT, HUME, HELVETIUS, HOLBACH) entre outros, preocuparam-se em sustentar a validade dos conceitos versados em Dei delitti e delle pene que reagia vigorosamente contra os expedientes barbáricos utilizados para desvendar os crimes e punir seus autores.

Inaugurava-se um estádio de promissão para o Direito Penal, na medida que a resposta ao ilícito pudesse ganhar proporcionalidade, objetivo inalcançado pelo Direito primitivo, dado o regime 
de penas absolutas em natureza e quantidade, com raras exceções, como as observadas no Império Romano (sob a influência da extraordinaria cognitio), no Direito Germânico e no Canônico, quando se facultava ao juiz a imposição de quantidades penais segundo as circunstâncias, porém, como homenagem deferida tão sòmente aos poderosos (CARRANCA Y TRUJILLO, 253).

A Escola Clássica incorporou ao seu repertório de dogmas, o critério da proporcionalidade entre pena e delito, enquanto a Esconla Positiva, repudiando tal relação entre coisas absolutamente hetero. gêneas como sustentou GIOVANNI BOVIO em 1878 (PESSINA, 63?) defendia a necessidade da pena ser individualizada, isto é, adaptada aos atributos pessoais do delinqüente, com o que também se cuidaria da defesa social pela inocuização do estado de periculosidade.

Para os positivistas, a pena, como ultima ratio da proteção social, não poderia ser apenas proporcional à gravidade objetiva do crime, mas deveria adequar-se à personalidade mais ou menos perigosa do delinqüente, com o seqüestro por tempo indeterminado, quer dizer, enquanto o condenado não estiver readaptado à vida livre e honesta, da mesma maneira que o doente entra no hospital não por um lapso prefixo de tempo - o que seria absurdo - mas durante o tempo necessário para readaptar-se à vida ordinária. (FERRI, 46)

A estimação da periculosidade (no senso naturalístico) do infrator como medida para a sanção, iá fôra cogitada por PLATÃO \& ARISTÓTELES, que afirmavam a necessidade da pena relacionar-se com a perversidade do infrator.

Quando FERRI substituiu o título de sua monumental obra 0 Homicídio por 0 Homicida, justificou sua atitude dizendo que na justiça penal cotidiana, não seria o estudo antropológico e estatístico do delito, como fato natural, que estaria em primeiro plano, mas c exame do crime como fenômeno jurídico em função de seu autor que é o protagonista da justiça penal (EUSEBIO GÓMEZ, 10).

2. O surgimento de penas segundo graus prefixados, revelou o interêsse legislativo em fundar um cistema de resposta apropriada à gravidade objetiva do fato e repousava em princípio já proclamado através da Declaração dos Direitos do Homem e do Cidadão (1789) segundo o qual A lei não deve estabelecer senão penas estritamente e evidentemente necessárias e ninguém pode ser castigado senão em virtude de uma lei estabelecida e promulgada anteriormente ao delito e legalmente aplicada (inciso oitavo).

Daí as normas do Código napolitano (1819) que se estenderam 
à legislação espanhola (Códigos de 1822, 1848) espalhando-se por vários países latinos.

O Código Criminal do Império brasileiro (1830) dispunha pelo artigo 63: Quando êste Código não impõe pena determinada, fixando sòmente o máximo e o mínimo, considerar-se-hão tres gráos nos crimes, com aftenção às suas circumstancias aggravantes ou attenuan. tes, sendo o maximo e de maior gravidade, a que se imporá o maximo da pena; o minimo o de menor gravidade, a que se imporá a pena minima; o médio o que fica entre o maximo e o minimo, a que se imporá a pena no termo médio entre os dois extremos dados.

Apesar das vicissitudes práticas, denunciadas através da jurisprudência, para se alcançar a média ponderável no concurso de circunstâncias agravantes e atenuantes, procurava o legislador nacional solucionar a difficil questão da proporcionalidade das penas aos delictos (F. LUIZ, 131).

Os defeitos do sistema, no entanto, foram anotados por juristas de nomeada, entre êles ZANARDELLI que em seu relatório acompanhando o Código italiano de 1889, salientou: Nulla maggiormente contrasta con la infinita varietà degli atti umani e con la non meno infinita gradazione dei moîi dell'animo, del dolo, della colpa, che lo stabilire dover essere quattro, cinque, otto questi gradi, quasichè pale numero possa a priori essere fissato dal legislatore (COSTA E SILVA, 248).

A mitigação do arbítrio judicial trazia como inevitável conseqüência, o esvaziamento da tarefa de individualização, reduzindo o julgador a um simples computador de porções aritméticas.

Mas o legislador brasileiro contemporâneo não se capacitou da experiência e repetiu no Código de 1890: Nos casos em que este codigo não impõe pena determinada e sómente fixa o maximo e o minimo, considerar-se-hão tres gráos da pena, sendo o gráo médio comprehendido entre os extremos, com attenção ás circumstancias aggravantes e attenuantes as quaes serão applicadas na conformidade do disposto no art. 38, observadas as regras seguintes: $\S 1 .^{\circ}$ No concurso de circumstancias aggravantes e aftenuantes que se compensem, ou na ausencia de umas e outras, a pena será applicada no gráo médio. § $22^{\circ}$. Na preponderancia das aggravantes a pena será applicada entre os gráos médio e maximo, e na das attenuantes entre - médio e o minimo. § $3 .^{\circ}$. Sendo o crime acompanhado de uma ou mais circumstâncias aggravantes sem alguma attenuante, a pena será applicada no maximo, e no minimo, si for acompanhado de uma ou mais circumstancias attenuantes sem nenhuma agravante. (art. 62) 
O mesmo critério foi observado na Consolidação das Leis Penais (1932, art. 62)

3. O vigente Código Penal do Brasil, acompanhou a tendência dos modernos textos que expungiram o arranjo dosimétrico, apenas considerando certas causas particulares de aumento ou diminuição em escalões determinados, correntes, verbi gratia, na tentativa, reincidência específica, conourso de crimes, etc. (Argentina, Panamá, México, Uruguai, Colômbia, Itália, Suiça, Grécia, Iugoslávia, entre outros).

A preferência por um método de resposta penal que consul tasse a gravidade objetiva do fato mas que não omitisse a inspeção de seu autor, vinha, entre nós, dos projetos SÁ PEREIRA (arts. 99 e 100) e ALCÂNTARA MACHADO (arts. 43 e 44).

Êste, adotava a seguinte técnica: Compete ao juiz, fundamentando a decisão: I - determinar a qualidade da pena aplicável, quando a lei estabelecer alternativamente mais de uma; II - determinar, dentro dos limites legaes, a quantidade da pena aplicável. $\S$ único - No exercício desses poderes, o juiz atenderá: I - à perso. nalidade do agente; II - às circunstâncias que agravam ou atenuam - crime; III - às causas de aumento ou diminuição da pena. Art. 44 - Para formar juizo sôbre a personalidade do agente, o juiz terá em conta: 1 - a idade, educação e situação econômica do réo, os seus antecedentes judiciais ou penais e procedimento na vida individual, familiar e social; II - o seu comportamento e estado de ânimo antes, durante e depois do crime; III - quaesquer outros elementos que contribuam para o conhecimento de seu temperamento e caráter.

4. Inspirando-se no artigo 133 do Código ROCCO, o Anteprojeto HUNGRIA (1963) dispõe: Para fixação da pena privativa de liberdade, o juiz aprecia a gravidade do crime praticado e a personalidade do réu, devendo ter em conta a maior ou menor extensão do dano ou perigo de dano, os meios empregados, o modo de execução, as circunstâncias de tempo e lugar, a intensidade do dolo ou grau de culpa, os antecedentes do réu, sua maior ou menor periculosidade ou capacidade para delinqüir, meio social em que vive, a sua atitude de insensibilidade, indiferença ou arrependimento após o crime (art. 50)

Na opinião de BASILEU GARCIA (131) a redação do texto não trouxe nenhuma contribuição de melhoria ao artigo 42 do atual Código, além de apresentar-se tautológica quando manda o juiz examinar os antecedentes do réu, o que seria desnecessário uma vez que ao se perquirir a personalidade, necessàriamente se indagaria a vida anterior que funciona como sua ilustração. 
O observação é improcedente, pois a verificação dos antecedentes do condenado é alinhada entre outras exigências para a obtenção de um dossier de personalité.

Com efeito, duas são as frentes de indagação: quanto à composição do fato e suas conseqüências: meio empregado, modo de execução, tempo, lugar, intensidade do dolo ou grau da culpa, extensão do dano ou perigo de dano; quanto à personalidade do infrator: antecedentes, maior ou menor periculosidade, capacidade para delinqüir, meio social em que vive, atitude de insensibilidade, indiferença ou arrependimento após o crime.

Logo, procurou apenas o anteprojeto instalar no elenco de índices obrigatórios, aquêles que mais necessàriamente devem ser criticados para se encontrar os aspectos de maior repercussão referentes ao ilícito e seu construtor.

HELENO CLAUDIO FRAGOSO, considerando a enumeração de diretivas cuidadosa e completa, opõe, no entanto, dois reparos: 0 primeiro é que logo no início haja referência à culpabilidade, como se faz no Código Suiço. Deve-se abandonar a fórmula muito equívoca "intensidade do dolo ou grau da culpa" que fomos buscar no Código Italiano (cf. Costa e Silva, Codigo Penal, 1943, p. 244). Assim, no art. 50 do anteprojeło, logo após a expressão "devendo ter em conta" deveria seguir-se a "culpabilidade, a maior ou menor extensão do dano etc. O segundo reparo é o seguinte: se se indica como elemento para a medição da pena, a consideração dos meios e modos de execução e das circunstâncias de tempo e lugar, é neces. sário ressalvar a hipótese em que tais elementos já são característicos do tipo. É o que se faz no projeto alemão (79/80).

As objeções do festejado cientista são inteiramente adequadas. A expressão culpabilidade como substituição às diretivas intensidade do dolo ou grau da culpa, além de ser mais completa por traduzir o elemento psicológico-normativo que informa a conduta punível, virá obviar os inconvenientes do cotidiano forense, pois muitos juízes ainda não apreenderam a correta inteligência de tais estágios anímicos do delito.

Para os comentadores do Código Penal italiano de 1930, a inter:sidade do dolo se refere à obstinação, à persistência do agente em relação ao seu propósito criminoso (SALTELLI - DI FALCO, 421).

JORGE SEVERIANO (148) não se conformava com a redação do Código brasileiro, nesta parte, pois o dolo não comportaria a divisão em intenso e não intenso, pela impossibilidade de se fracionar 0 processo volitivo. 
Por outro lado, é difícil a compreensão do que seja grau da culpa que escritores peninsulares como MAGGIORE e NINO LEVI entendem estar subsumido no fenômeno da previsibilidade, louvando-se na distinção civilística entre culpa ampla, leve e levíssima, que forneceria um critério prático diante dos casos particulares.

A melhor doutrina, porém, dirige-se no sentido de não ser possível o estabelecimento apriorístico de uma regra geral para a interpretação em tese (SALTELLI - DI FALCO, 421).

Os dados relativos ao meio empregado, modo de execução, tempo e lugar, definidos pelo Código Penal italiano como circunstâncias objetivas (art. 70), sòmente influenciarão a medida judicial da pena, desde que não componham o tipo, como ocorre, por exemplo no homicídio qualificado. Daí porque a sugestão oportuna para se ressalvar a hipótese, conjurando-se o eventual perigo de um bis in idem ou, quando menos, uma extravagância didática da lei.

Aliás, o projeto de Código Penal português (1963) esclarece que as circunstâncias modificadoras da medida penal reconhecidas pelo juiz, são as que não fazendo parte do tipo legal do crime, militam a favor ou contra o delinqüente. (art. 86)

5. Evidentemente deslocada, parece-nos, a cogitação sôbre a maior ou menor periculosidade do réu, uma vez que esta forma de levantamento pessoal interessa à medida de segurança, como seu suporte naturalístico e não está submetida ao juízo de censurabilidade que estrutura a culpabilidade e, por via de conseqüência, a pena.

Desde que o Anteprojeto HUNGRIA repeliu o sistema do duplo binário, não se justifica que, no momento da imposição da reclusãu ou detenção, se consulte a periculosidade do destinário da sanção.

Quanto à capacidade para delinqüir, que a colocação no anteprojeto faz supor mesmeidade com o estado perigoso (quando se diz maior ou menor periculosidade OU capacidade para delinqüir), o que é inadmissível, deve ser entendida como visão do passado até o presente (perversidade na comissão do delito, postura contemporânea e sucessiva) e não como perspectiva de futuro (probabilidade de reiteração no ilícito) permitindo, assim, a análise de reprovação, pois nel cuore del concetto di capacità a delinquere giace il carattere della persona, il quale à concetto che si presta ad una valutazione etica ed a formare cosi un criterio per la comisurazione della colpa e delía pena in senso diverso daquello prospettato dai naturalisti (BETTIOL, 630). 
6. A capacidade para delinqüir, resulta: dos motivos que informaram a conduta; do caráter do réu; de seu estilo de vida pregressa; do comportamento coetâneo ou posterior ao delito e das condições de vivência individual, familiar e social. Trata-se, portanto, de encontrar a personalidade que se poderia chamar de psicológica.

Evidentemente, qualquer condicionamento mórbido da personalidade que tenha proporções de interferir no processo causal-psíquico, deverá ser criticado com referência à imputabilidade e não no plano da culpabilidade.

A doença mental, o desenvolvimento mental incompleto ou retardado, a grave alteração de consciência e outras formas de desvios que impermitem a livre projeção da conduta e sua valorização ética, anulam a possibilidade da auło-censura, que é o núcleo da culpabilidade.

7. A perquirição do fato e seus coeficientes e a visão da personalidade (capacidade para delinqüir) do culpado, não poderão ser promovidas por um critério de preferência, eis que fato e autor estão distanciados apenas cronologicamente, giacchè il giudice deve in primo luogo tener conto della gravità del reato $\mathrm{e}$ in secondo luogo inquadrare il reato nella personalità dell'agente (BETTIOL, 629).

O julgador examinará primeiramente a composição física e moral do evento e as conseqüências da ação, apreciando após a personalidade do infrator, pois como lembra BETTIOL, il nostro è un diritto penale che guarda al fatto (629) sem prejuízo da consideração sôbre - agente que empresta valor e significação ao quadro meramente conceitual do acontecimento típico.

Mas, quando se fala em conseqüências da ação, não se pretende referir aos resultados naturalísticos sem vinculação à culpabilidade, pois o dano ou perigo de sua verificação só serão penalmente relevantes desde que estejam na linha do desdobramento causal objetivo do autor.

BELING já ressalvava as circunstâncias objetivas de agravação que não eram imputáveis à culpa do agente e, portanto, não funcionavam para a exasperação penal (166).

MAURACH (539) referindo-se ao recente projeto de Código Penal alemão, transcreve o parágrafo 62 que, a respeito do tema da med:ção da pena fala nas culpáveis conseqüências do fato.

Tal advertência reproduz a preocupação do legislador tedesco, no sentido de que a pena não deve ultrapassar a medida da culpabi. lidade ( $\S 2:^{\circ}$ do mesmo projeto). 
Diz ainda o renomado penalista que as circunstâncias externas do ato realizado constituem um ponto de partida puramente provisório e não vinculatório. A gravidade externa do fato ùnicamente pode-se juntar ao autor desde que seja subjetivamente reprovável. (541)

Assim, desde que o resultado da ação para ganhar relêvo jurídico-penal sempre deve ser analisado em função da culpabilidade, a tarefa de mensuração da pena não pode ser feita com prevalência do fato sôbre seu construtor, porém num plano de equilíbrio, atendendo-se o interêsse da sociedade e do culpado, uma vez que a sanção é retributiva e deve ter em conta a prevenção especial.

8. A constante busca de fórmulas mais evoluídas para a individualização da pena, é revelada pelo comportamento do legislador de modernos textos.

Nas Bases da Legislação Penal Soviética, aprovadas pelo Sovieto Supremo da URSS em 25 de dezembro de 1958, consignou-se através do artigo 32, sob o título Princípios gerais da determinação da pena, o seguinte: 0 Tribunal determina a pena dentro dos limites estabelecidos pelo artigo de lei que estabelece a responsabilidade para o delito cometido, em estrita conformidade com as disposições das presentes bases do Código Penal da República Federada. Ao determinar a pena, o Tribunal, guiando-se pela consciência jurídica socialista, toma em conta o caráter e o grau de periculosidade social do crime cometido, a personalidade do delinqüente e as circunstâncias do fato que atenuam ou agravam a responsabilidade.

Em seqüência, os artigos 33 e 34 enumeram as circunstâncias atenuantes e agravantes.

Se é certo que o texto recomenda a observação do fato e seu autor, por um critério meta-jurídico (através da consciência jurídica socialista) o que nos lembra o conceito material do delito no regime do Direito Penal autoritário da Alemanha nazista, quando a antijuridicidade era a rebeldia ao são sentimento do povo interpretado pelo Führer, também é verdade que o legislador soviético atual considerou imprescindível o exame da pessoa do delinqüente e das circunstâncias vinculadas ao fato, muitas delas de caráter subjetivo, permitindo, ainda, que na fixação da pena o Tribunal considere atenuantes não previstas em lei. (art. 33).

O recente projeto de Código Penal argentino (1960) elaborado por SEBASTIAN SOLER, recomenda que o tribunal deve tomar conhecimento direto e de visu do sujeito e, na medida exigida pelo caso, da vítima e das circunstâncias do fato (art. 73).

Esta norma de excelente política criminal já consta do Código 
mexicano (1931) através do artigo 52: O juiz deverá tomar conhecimento direto do sujeito, da vítima e das circunstâncias do fato, na medida requerida para cada caso.

Como se observa, tais disposições são mandamentais e reclamam a vinculação pessoal do juiz à causa, em têrmos de identidade física que, entre nós, ocorre tão sòmente para as contravenções penais conforme tem admitido a jurisprudência.

No procedimento criminal, o levantamento histórico do fato $\Theta$ de seus coeficientes, bem como a crítica do autor, devem ser promovidos pelo mesmo juiz que diretamente colheu as declarações do imputado, ouviu testemunhas e peritos, cuidando, assim, da reconstrução dos episódios de maneira a se aproximar tanto quanto possível da verdade, que é o escopo da ação penal.

A opinião ligeira de que o interrogatório é ato de defesa, tem conduzido julgadores despreparados a omissões imperdoáveis, pois frente ao Código de Processo Penal brasileiro, o silêncio do réu às perguntas que lhes são dirigidas poderá ser interpretado em seu prejuízo (art. 186) e a indiferença para com os fenômenos colateràis ao evento típico, porém ligados ao fato ou seu construtor, tem gerado a redação de sentenças imprestáveis quanto à fixação da pena.

Em geral, transcreve-se o texto do Código Penal que exige a individualização, quer porque o juiz não atentou para a inteligência das diretivas, quer porque a instrução tornou-se vazia, pois a pesquisa se subsumiu apenas na constatação da essência fática da imputação e sua autoria.

EDUARDO CORREIA (335) anuncia que os projetos de códigos penais da atualidade apresentam uma série de critérios orientadores para a mensuração, procurando expungir o arbítrio total e, sobretudo, obrigando à motivação da sentença no instante da individualização, sob pena de poder ser modificada pela instância de revisão. No mesmo sentido, alguns temas da AIDP em Atenas, no ano de 1955.

Em seu projeto de Código Penal, o referido jurista fêz constar: $\mathrm{Na}$ sentença devem ser expressamente referidos os fundamentos da medida da pena ( $\S$ único do art. 86).

De que vale a acurada dissertação a respeito da gravidade do fato e da declaraçã̃o de culpabilidade, como prestação jurisdiciona! devida à sociedade, se o julgador é extremamente econômico ao examinar a personalidade do autor?

Tinha razão LAERTES $M$. MUNHOZ quando ponderava: 0 exame da pessoa do delinqüente é como a essência da própria individuali- 
zação e de tal maneira deve operar na fixação da quantidade da pena, que 0 próprio fato delituoso, nas suas circunstâncias objetivas, fica relegado a um plano inferior (3).

Em outubro de 1963, o Govêrno Leone apresentou ao Parlamento Italiano um projeto de lei delegada para a reforma do Código Penal. Fundado na Constituição, o projeto informava quais os primados que norteariam alguns textos do nôvo Código e entre êles merece referência o atinente à atribuição ao juiz de um maior pode، discricionário na medida concreta da pena, com o objetivo de assegurar melhor proporcionalidade às condições subjetivas do condenado.

Tal movimento está em consonância com o artigo $27,3 .{ }^{\circ}$, período, da Constituição da Itália, que trata do princípio da humanização da pena, compreendendo-se humanização como o processo tendente a obter a efetiva ressocialização do delinqüente.

9. Na pauta de temas para o Décimo Congresso Internacional de Direito Penal que se realizará em Roma (1969) consta o relativo à divisão do processo penal em duas fases.

Conforme o primeiro Documento de trabalho editado pelo Grupo Brasileiro da Associação Internacional de Direito Penal, que, entre seus membros conta com o Professor HELENO CLAUDIO FRAGOSO. são divulgadas as seguintes notas, com o objetivo de limitar o tema e indicar as questões a estudar: a) Por "pena" deve-se entender tôdas as sanções penais tendentes a reprimir as infrações, conseqüentemente assim as medidas preventivas como as penalidades pròpria. mente ditas (sejam elas privativas de liberdade, de direitos ou outros) e, ademais aquilo que se segue à pena sofrida parcial ou totalmente (por exemplo a libertação condicional e as obrigações penais posteriores); b) Determinação e aplicação das penas não poderiam opor-se formalmente. A aplicação não é senão a determinação ao caso concreto. É assim que, nos dois casos, defrontam-se problemas relativos à natureza da pena e sua duração, aquêles que concernem ao estabelecimento de detenção (prisão fechada, aberta ou semi-aberta, prisão escola, centro de formação profissional, efc...) ou ao modo de execução (encarceramento, detenção segundo o sistema auburniano, regime progressivo, semi-liberdade, trabalho exterior, campo de trabalho, etc...). Convém então perguntar-se em que medida a pena deve ser determinada desde o estágio da condenação. (Em diversos países, autoridades especiais têm o poder de intervir na dełerminação e aplicação das penas: tribunal de execução das penas, juiz de aplicação das penas, comissões mistas 'adult and young authorities', efc...); c) Desde logo, o papel do tribunal que primitivamente decidiu deve se rexaminado, sobretudo levando em consideração: 
1. As disposições legais (especialmente em casos de penas fixas);

2. O especialista que pode estar destinado a dar um parecer sôbre a pena em função da personalidade do sujeito;

3. A administração encarregada da execução da pena;

4. As outras autoridades que intervirão posteriormente à senrença original.

Recomenda o mesmo Documento de trabalho que está fora de cogitação tudo o que concerne ao processo de informação e julgamento, o que interessa à declaração de culpabilidade e todos os problemas particulares aos delinqüentes menores e às jurisdições para crianças e adolescentes. (cf. cópia distribuída por ocasião do Colóquio promovido na Guanabara de 23 a 28 de outubro de 1967).

10. Na primeira fase do processo, o objeto da perquirição recairá tão sòmente no levantamento histórico do fato e sua autoria para o reconhecimento da conduta eventualmente típica, antijurídica e culpável, abstraídas as pesquisas de fundo sôbre a personalidade do imputado.

Entendo que o juiz, nesse estágio, deverá indagar sôbre o concretude do acontecimento (adequação típica); as circunstâncias objetivas (tempo, lugar, meio empregado, modo de execução) e as conseqüências culpáveis da ação (dano ou perigo de dano) além de outros dados enumerados pela lei como causas particulares de au. mento ou diminuição.

Também a intensidade do dolo ou o grau da culpa (enquanto não se adotar a fórmula suíça) devem ser apurados, pois embora se considerem como circunstâncias subjetivas, já se desprenderam do mundo espiritual do autor para se vincularem ao fato, qualificando-o especialmente.

O extrato da pesquisa será pôsto no relatório da sentença, contemporâneamente à declaração do estado de culpa.

Em seguida, o juiz passará à segunda frente de instrução, dedicada exclusivamente aos comemorativos pessoais do agente. Para tanto, contará com a participação efetiva da acusação e defesa agora debatendo exclusivamente sôbre a qualidade e quantidade da sanção.

Alguns elementos relativos aos aspectos familiar, profissiona!, social, etc. já teriam sido colhidos durante a primeira etapa de instrução, através da prova testemunhal ou documental, que, ao mesmo tempo, informasse a respeito do fato e seu autor, obviando-se, assim, o trabalho de fracionamento da prova, com prejuízos à celeridade do procedimento. 
Desde que a prova testemunhal interessasse exclusivamente ao levantamento da personalidade, seria colhida na segunda fase do processo, possibilitando-se a economia processual sem as protelações que tanto oneram o conceito popular do magistério punitivo.

Enquanto não fôr possível a especialização dos juízes criminais, tida como necessária através de vários Congressos de Direito Penal (Londres (1925); Palermo (1933); Roma (1938) a presença do espe. cialista da Medicina é imprescindível para o estudo psico-criminoló. gico, quer através das informações oriundas da prova, quer por meio de inspeção direta.

Encerrada a instrução complementar, que terá duração muito menor que a original, em face da limitação do objeto, as partes arrazoarão, fixando-se na forma e medida da sanção, eis que a culpabilidade já estará reconhecida por despacho anterior.

As leis de processo estabelecerão os prazos para a colheita de elementos de convicção sôbre a capacidade para delinqüir, oferecimento de alegações e sentença de individualização penal, bem como dos recursos de primeiro grau (relativo à declaração de culpabilidade) e de segundo grau (referente à fixação da sanção) e bem assim de quaisquer incidentes processuais que reclamem um tratamento nor mativo.

Mas, é bem de ver que para o segundo estágio não se cuidará apenas da resposta penal no aspecto de imposição, de quantidade e qualidade. Isso porque o juiz terá sua competência prorrogada para fiscalizar e decidir os problemas da execução e qualquer outra ques tão relativa ao aspecto didático da sanção. A jurisdição se exaure com a extinção da pena.

11. A tendência de ressocialização do condenado ganhará perspectivas mais otimistas, desde que tôdas as ocorrências da fase administrativa da individualização sejam consideradas através do processo, exigindo-se, assim, uma atuação mais eficiente do Poder Judiciário durante o itinerário da execução penal.

Desta forma se poderá cuidar do destino da pena que tem sido expressamente previsto em textos modernos: Anteprojeto Hungria, art. 35, Bases da Legislação Penal Soviética, art. 20, Projeto Soler, art. 34, etc.

Êsse destino da resposta penal exprime a doutrina da prevenção especial.

A experiência tem demonstrado que a pena não poderá mais manter a secular característica da retribuição, com o esquecimento do 
destinatário, o qual, sem integrar-se num efetivo programa de recuperação, constitui-se, pessoalmente, num ser atrofiado em esperança e, socialmente, num perigo à reincidência.

O aspecto da retribuição só é relevante enquanto a pena é cominação, por atender o requisito da proporcionalidade entre a gravidade objetiva do fato e a resposta absirata através da sanção, face as referências da qualidade do bem jurídico atingido ou pôsto em risco de lesão pelo delinqüente e dos coeficientes vinculados ao acontecimento e considerados pela lei como causas gerais e especiais de modificação da pena.

A partir de então, a pena estará socialmente justificada, devendo a Justiça cuidar da pessoa do autor, exclusivamente, propiciando-lhe condições para a readaptação durante a fase penitenciária.

\section{BIBLIOGRAFIA}

1. CARRANCA Y TRUJILlO, Derecho Penal Mexicano, parte general, II - Antiguz Libreria Robredo, México, 1964.

2. ENRICO PESSINA, Elementos de Derecho Penal, Ed. Reus S/A, Madrid, 1936.

3. ENRICO FERRI, Princípios de Direiło Criminal, Saraiva e Cia., São Paulo, 1931.

4. EUSEBIO GÓMEZ, Delincuencia Político-Social, Libreria y Editorial La Facultad, Buenos Aires, 1933.

5. FRANCISCO LUIZ, Código Criminal Anotado, Maceió, 1885.

6. COSTA E SILVA, Código Penal, São Paulo, 1943.

7. BASILEU GARCIA, As Penas e sua Aplicação no Anteprojeło, conferência em Ciclo de Conferências sôbre o Anteprojeto do Código Penal Brasileiro, São Paulo, 1965.

8. HELENO CLAUDIO FRAGOSO, A reforma da legislação Penal (I) - Revisła Brasi leira de Criminologia e Direito Penal, n. ${ }^{\circ}$ 2, 1963.

9. CARLO SALTELLI - ENRICO ROMANO DI FALCO, Commento Teorico-Prático del Nuovo Codice Penale, vol 1, Unione Tipografico-Editrice Torinese, Torino, 1931.

10. JORGe SEVERIANO, Código Penal dos Estados Unidos do Brasil, vol. 2. ${ }^{\circ}$ - Livraria Jacintho - Editora, Rio de Janeiro, 1941.

11. GIUSEPPE BETTIOL, Diritto Penale, parte generale, G. Priula, Editore, Palermo, 1962.

12. ERNST VON BELING, Esquema de Derecho Penal - La Doctrina del Delito-Tipo, Editorial Depaima, Buenos Aires, 1944.

13. REINHART MAURACH, Trałado de Derecho Penal, II, Ediciones Ariel, Barcelona, 1962.

14. EDUARDO CORREIA, Direito Criminal, II, Livraria Almedina, Coimbra, 1965.

15. LAERTES M. MUNHOZ, Alguns aspectos da individualização da pena, Forum do Paraná, n. ${ }^{\circ} 12,1963$ - artigo. 